\title{
A STUDY OF POTENTIAL TOXIC EFFECTS AFTER REPEATED 10-WEEK ADMINISTRATION OF A NEW IRON CHELATOR - SALICYLALDEHYDE ISONICOTINOYL HYDRAZONE (SIH) TO RABBITS
}

\author{
Ivona Klimtová ${ }^{1}$, Tomáš Šimůnek ${ }^{1}$, Yvona Mazurová ${ }^{2}$, Jana Kaplanová ${ }^{3}$, Martin S̆těrba ${ }^{4}$, Radomír Hrdina ${ }^{1}$, Vladimír Geršl $^{4}$, \\ Michaela Adamcová ${ }^{5}$, Přemysl Poňka
}

Charles University in Prague, Faculty of Pharmacy in Hradec Králové: Department of Pharmacology and Toxicology ${ }^{1}$; Faculty of Medicine in Hradec Králové: Department of Histology and Embryology ${ }^{2}$, Department of Paediatrics ${ }^{3}$, Department of Pharmacology ${ }^{4}$, Department of Physiology ${ }^{5}$, McGill University, Montreal, Quebec: Department of Physiology and Medicine ${ }^{6}$

Summary: Salicylaldehyde Isonicotinoyl Hydrazone (SIH) - a Pyridoxal Isonicotinoyl Hydrazone (PIH) analogue - is an effective iron chelator with antioxidant and antimalarial effects, as documented in numerous in vitro studies. However, no toxicological data obtained from in vivo studies have been made available yet. In this study, the potential toxic effects of repeated administration of SIH ( $50 \mathrm{mg} / \mathrm{kg}$, once weekly, 10 weeks, i.p.), partially dissolved in a $10 \%$ Cremophor solution, on various biochemical, haematological, and cardiovascular parameters and on morphology of selected tissues were investigated in rabbits. The obtained values were compared with data from the control (saline, $1 \mathrm{ml} / \mathrm{kg}$, i.v.) and the Cremophor (10\% Cremophor solution, $2 \mathrm{ml} / \mathrm{kg}$, i.p.) groups. In this study, SIH did not induced marked signs of toxicity: No premature deaths occurred, the body weight increase was comparable with the control and Cremophor groups. Only few and mild changes in some biochemical and haematological parameters could be determined, most of them were noticed also in the control or Cremophor groups. The morphological changes in the kidney were mild and did not manifest in the biochemical examination. The cardiac function was also not affected markedly - the values of left ventricular ejection fraction and systolic time interval did not differ from the values of control group. Only an increased left ventricular contractility $\left(\mathrm{dP} / \mathrm{dt}_{\max }\right)$ was noticed in the SIH group at the end of the experiment as compared to the controls (13354 \pm 1191 vs. $9339 \pm 647 \mathrm{mmHg} / \mathrm{s}$, resp.). These results seem to be promising from the standpoint of possible clinical use of SIH.

Key words: Salicylaldehyde isonicotinoyl hydrazone (SIH); Iron chelator; Rabbit; Biochemistry; Haematology; Cardiovascular; Histology

\section{Introduction}

Iron $(\mathrm{Fe})$ is an element essential for life, but its excessive amount may become very toxic to various tissues. Fe chelators have been primarily developed for the treatment of $\mathrm{Fe}$ overload diseases, such as $\beta$-thalassemia. However, the knowledge of the role of $\mathrm{Fe}$ in the generation of free radicals as well as in the metabolism of tumour cells and parasites is the basis for the introduction of Fe chelation for the therapy of some pathological conditions, e.g. free radicalmediated injury, malaria, or some types of cancer $(4,12$, 16,17).

At present, deferrioxamine (DFO) is the only Fe chelator used in clinical practice. Although DFO is a highly effective drug with relatively few side effects, it suffers from a number of disadvantages, including its high cost and poor intestinal absorption. That is why the development of new non-toxic, effective, orally active and inexpensive Fe chelator is needed. One group of compounds that could satisfy these criteria is that of the pyridoxal isonicotinoyl hydrazone (PIH) class. The chelators of the PIH group are tridentate and have predominantly a neutral charge at physiological $\mathrm{pH}$, allowing them passage through cell membranes and access to intracellular Fe pools. They are characterized by a high affinity and selectivity for $\mathrm{Fe}$ and a low affinity for other biologically important ions, such as $\mathrm{Ca}$ (II) and $\operatorname{Mg}$ (II) $(16,17)$. The results of studies evaluating the toxicity of PIH are also very promising $(10,19,20,21)$. In our studies, i.p. administration of PIH in a dose of $50 \mathrm{mg} / \mathrm{kg} /$ week for 10 weeks did not induce any signs of toxicity in rabbits $(19,20)$.

Salicylaldehyde isonicotinoyl hydrazone (SIH) is a PIH analogue with high Fe chelation activity and antioxidant and antimalarial actions demonstrated in vitro $(1,6,8,9,13$, 
$16,17,18,24,25)$. However, there is only one in vivo study, where the antimalarial effect of SIH was tested in mice (6). The potential toxic effects of SIH in vivo were not examined in any of the available studies.

In this study, the effects of SIH on biochemical and haematological parameters and various parameters of cardiac function were investigated in the course of its repeated intraperitoneal administration in rabbits. Furthermore, changes in body weight and histological changes in some organs were examined. As many of effective chelators cannot be used in the clinical practice due to their toxicity, toxicological data are considered to be essential from the viewpoint of a possible therapeutic use of a drug.

\section{Methods}

Chemicals: salicylaldehyde isonicotinoyl hydrazone SIH (P. Poňka, McGill University, Montreal, Canada), Cremophor EL (Sigma-Aldrich, Czech Republic), ketamine (Calypsol inj., Chemical Works of Gedeon Richter LTD, Hungary), Aqua pro injectione (Biotika, Slovakia), pentobarbital (Nembutal Sodium, Abbott, U.S.A.)

Experimental design: Medium-size Chinchilla male rabbits of average weight of $3.6 \mathrm{~kg}$ at the beginning of the experiment were used. All procedures were performed in accordance with the "Guide for the care and use of laboratory animals" (1996) and were under the supervision of the Ethical Committee of the Medical Faculty in Hradec Králové. SIH partially dissolved in a $10 \%$ Cremophor solution was administered intraperitoneally to 8 rabbits in a dose of $50 \mathrm{mg} / \mathrm{kg}$ once weekly for 10 weeks. Control group (11 animals) received saline ( $1 \mathrm{ml} / \mathrm{kg}$, intravenously). Furthermore, 12 rabbits were given a $10 \%$ Cremophor solution $(2 \mathrm{ml} / \mathrm{kg})$, intraperitoneally. All manipulations were performed under ketamine anaesthesia $(50 \mathrm{mg} / \mathrm{kg}$, i.m. $)$. Noninvasive echocardiographic examination as well as polygraphic recordings (systolic time intervals) was performed before the $1^{\text {st }}$ administration, in the $5^{\text {th }}$ and $7^{\text {th }}-11^{\text {th }}$ weeks. Arterial blood was sampled before the $1^{\text {st }}, 5^{\text {th }}$ and $8^{\text {th }}$ administrations and at the end of the experiment (5-7 days after the $10^{\text {th }}$ administration) for the evaluation of biochemical parameters and before the $1^{\text {st }}$ and $5^{\text {th }}$ administrations and at the end of the experiment for the evaluation of haematological parameters. In the $11^{\text {th }}$ week, invasive haemodynamic measurements were performed. Then the rabbits were sacrificed by an overdose of pentobarbital and the heart, liver and kidney were examined histologically. The weight of rabbits was observed every week before administration of drugs.

Biochemical and haematological parameters: Standard biochemical parameters were determined in plasma/serum using a Hitachi 717 analyser (Japan). Haematological parameters were measured by means of a Coulter T890 counter (USA).

Echocardiographic measurements: The left ventricular systolic function was assessed using a GE Vingmed CFM
800A echocardiograph equipped with a standard pediatric 7,5 $\mathrm{MHz}$ probe. The left ventricular ejection fraction (LV EF) as a sensitive index of the left ventricular systolic function was calculated from the values of end-systolic and end-diastolic diameters which were determined by conventional steered $\mathrm{M}$ mode echocardiography from the parasternal long axis view. The measurements of left ventricular dimensions were also carried out from 2D images from the parasternal short axis view at the level of papillary muscles.

Systolic time intervals: The systolic time intervals were measured noninvasively by simultaneous recording of the ECG, phonocardiogram, and external carotid arterial pulse, using a Polygraph ADI PowerLab/8SP, software Chart for Windows (v. 3.4.11). On the basis of the left ventricular ejection time (LVET) and pre-ejection period (PEP) values, the PEP/LVET ratio was used as an index of the left ventricular systolic function.

Invasive haemodynamic measurement: At the $11^{\text {th }}$ week, heart rate, blood pressure in the femoral artery, and left ventricular maximal pressure rise in the isovolumic phase of systole $\left(\mathrm{dP} / \mathrm{dt}_{\max }\right)$ were measured invasively using a Polygraph ADI PowerLab/8SP and software Chart for Windows (v. 3.4.11) in pentobarbital-anaesthetized rabbits $(30 \mathrm{mg} / \mathrm{kg}$, i.v.). All parameters were recorded after a $15 \mathrm{mi}-$ nute-equilibration period.

Histological examination: Tissue blocks of the transversely sectioned left and right cardiac ventricles, left kidney, left liver lobule, left caudal lung lobule, duodenum (approx. $3 \mathrm{~cm}$ below the pyloric sphincter), and striated muscle tissue (from the left quadriceps femoral muscle) were fixed by immersion in $4 \%$ formaldehyde. Paraffin sections $(6 \mu \mathrm{m}$ thick) were stained with haematoxylin-eosin $(\mathrm{H}(\mathrm{E})$ and Masson's blue trichrome. Microphotographs were made with MicroImage software, version 4.0 (Media Cybernetics, Silver Spring MD, USA) at the Department of Radiobiology and Immunology, Purkyně Military Medical Academy in Hradec Králové.

Statistical analyses: Data are declared as mean \pm S.E.M. Significance was estimated by an ANOVA unpaired test (comparison between the groups) or paired t-test (comparison with the initial value within one group). Data without an underlying normal distribution were evaluated using the nonparametric Kruskal-Wallis ANOVA on Ranks test. P $\leq$ 0.05 was used as a level of statistical significance.

\section{Results}

Body weight: A significant body weight increase was present in all groups (Fig. 1); the body weight gain at the end of the experiment was $108.0 \%$ in the control, $110.5 \%$ in the Cremophor, and $109.8 \%$ in the SIH group, resp. No premature deaths of animals occurred following the administration of SIH or in other groups.

Biochemical parameters: Repeated administration of SIH caused a significant decrease in plasma levels of calcium, and phosphates and an increase in Fe, lactate de- 
Tab. 1: Changes of selected biochemical parameters during the experiment.

\begin{tabular}{|c|c|c|c|c|}
\hline Parameter/group & $\begin{array}{l}\text { before the } I^{\text {st }} \\
\text { administration }\end{array}$ & $\begin{array}{l}\text { before the } 5^{\text {th }} \\
\text { administration }\end{array}$ & $\begin{array}{l}\text { before the } 8^{\text {th }} \\
\text { administration }\end{array}$ & $\begin{array}{l}\text { 5-7 days after the } \\
10^{\text {th }} \text { administration }\end{array}$ \\
\hline \multicolumn{5}{|l|}{ Sodium (mmol/l) } \\
\hline control & $137 \pm 1$ & $138 \pm 1$ & $140 \pm 1$ & $140 \pm 0.4 \mathbf{i}$ \\
\hline Cremophor & $140 \pm 1$ & $141 \pm 1$ & $143 \pm 1$ & $143 \pm 1$ \\
\hline SIH & $142 \pm 1 \mathrm{c}$ & $144 \pm 1$ & $141 \pm 1 \#$ & $143 \pm 1$ \\
\hline \multicolumn{5}{|c|}{ Potassium $(\mathrm{mmol} / \mathrm{l})$} \\
\hline control & $3.4 \pm 0.1$ & $3.3 \pm 0.1$ & $3.4 \pm 0.1$ & $3.2 \pm 0.1$ \\
\hline Cremophor & $3.7 \pm 0.1$ & $3.6 \pm 0.1$ & $3.5 \pm 0.1$ & $3.4 \pm 0.2 \mathbf{i}$ \\
\hline $\mathrm{SIH}$ & $3.6 \pm 0.1$ & $3.5 \pm 0.2$ & $3.8 \pm 0.1 \mathrm{k}$ & $3.4 \pm 0.1$ \\
\hline \multicolumn{5}{|l|}{ Calcium (mmol/1) } \\
\hline control & $3.05 \pm 0.06$ & $3.14 \pm 0.04$ & $3.36 \pm 0.04 \mathbf{i}$ & $3.08 \pm 0.19$ \\
\hline Cremophor & $2.94 \pm 0.05$ & $3.06 \pm 0.04$ & $3.14 \pm 0.04$ i\# & $2.89 \pm 0.04$ \\
\hline $\mathrm{SIH}$ & $3.32 \pm 0.04 \# \mathbf{c}$ & $3.15 \pm 0.02 \mathrm{i}$ & $3.19 \pm 0.03 \mathbf{i}$ & $2.95 \pm 0.06 \mathbf{i}$ \\
\hline \multicolumn{5}{|c|}{ Phosphates (mmol/l) } \\
\hline control & $1.82 \pm 0.12$ & $1.47 \pm 0.08$ & $1.41 \pm 0.06 \mathbf{i}$ & $1.39 \pm 0.12 \mathbf{i}$ \\
\hline Cremophor & $2.17 \pm 0.25$ & $1.60 \pm 0.05$ & $1.42 \pm 0.06 \mathbf{i}$ & $1.49 \pm 0.11 \mathbf{i}$ \\
\hline $\mathrm{SIH}$ & $1.93 \pm 0.08$ & $1.67 \pm 0.06$ & $1.71 \pm 0.06$ & $1.51 \pm 0.09 \mathbf{i}$ \\
\hline \multicolumn{5}{|l|}{ Iron $(\mu \mathrm{mol} / 1)$} \\
\hline control & $40.9 \pm 4.0$ & $37.2 \pm 2.0$ & $32.6 \pm 1.7$ & $42.4 \pm 2.6$ \\
\hline Cremophor & $34.2 \pm 1.7$ & $32.1 \pm 2.1$ & $27.3 \pm 2.5$ & $43.7 \pm 2.7 \mathbf{i}$ \\
\hline $\mathrm{SIH}$ & $32.9 \pm 2.7$ & $36.0 \pm 3.7$ & $34.2 \pm 3.3$ & $46.4 \pm 2.9 \mathbf{i}$ \\
\hline \multicolumn{5}{|l|}{ Urea $(\mathrm{mmol} / \mathrm{l})$} \\
\hline control & $7.5 \pm 0.4$ & $7.4 \pm 0.3$ & $6.8 \pm 0.4 \mathbf{i}$ & $6.8 \pm 0.4 \mathbf{i}$ \\
\hline Cremophor & $7.1 \pm 0.5$ & $6.0 \pm 0.3$ & $6.1 \pm 0.4$ & $7.2 \pm 1.0$ \\
\hline SIH & $7.2 \pm 0.6$ & $7.6 \pm 0.4$ & $6.1 \pm 0.3$ & $7.0 \pm 0.5$ \\
\hline \multicolumn{5}{|l|}{ LD $(\mu \mathrm{kat} / 1)$} \\
\hline control & $8.94 \pm 1.27$ & $6.28 \pm 0.96$ & $7.27 \pm 0.83$ & $7.69 \pm 0.82$ \\
\hline Cremophor & $5.85 \pm 0.74$ & $5.66 \pm 0.68$ & $6.47 \pm 0.68$ & $8.98 \pm 0.82 \mathbf{i}$ \\
\hline $\mathrm{SIH}$ & $7.66 \pm 0.72$ & $10.74 \pm 1.32$ \#c & $13.78 \pm 1.51$ \#ci & $12.31 \pm 1.06 \# \mathbf{~ i}$ \\
\hline \multicolumn{5}{|l|}{ Proteins (g/1) } \\
\hline control & $62.3 \pm 1.1$ & $63.9 \pm 0.9$ & $66.6 \pm 1.2 \mathbf{i}$ & $64.2 \pm 1.1$ \\
\hline Cremophor & $62.8 \pm 1.4$ & $62.9 \pm 1.1$ & $63.8 \pm 1.0$ & $60.1 \pm 0.9 \#$ \\
\hline $\mathrm{SIH}$ & $65.3 \pm 1.2$ & $64.7 \pm 0.9$ & $63.2 \pm 1.3$ & $62.0 \pm 1.3$ \\
\hline \multicolumn{5}{|l|}{ Albumin (g/l) } \\
\hline control & $54.6 \pm 1.4$ & $54.7 \pm 0.7$ & $55.5 \pm 0.6$ & $53.5 \pm 1.1$ \\
\hline Cremophor & $56.5 \pm 0.7$ & $55.5 \pm 0.8$ & $56.5 \pm 0.7$ & $53.4 \pm 0.8 \mathbf{i}$ \\
\hline SIH & $53.4 \pm 0.8$ & $54.6 \pm 1.0$ & $51.6 \pm 1.3$ \#c & $52.7 \pm 0.9$ \\
\hline \multicolumn{5}{|c|}{ Glutathione $(\mathrm{mg} / \mathrm{g} \mathrm{Hb})$} \\
\hline control & $2.44 \pm 0.16$ & $3.41 \pm 0.45$ & $2.59 \pm 0.25$ & $5.14 \pm 0.69 \mathbf{i}$ \\
\hline Cremophor & $5.09 \pm 0.46 \#$ & $3.58 \pm 0.51$ & $4.55 \pm 0.58 \#$ & $3.58 \pm 0.25$ \\
\hline $\mathrm{SIH}$ & $6.09 \pm 0.46 \#$ & $4.55 \pm 0.59$ & $2.97 \pm 0.47 \mathbf{i}$ & $3.96 \pm 0.67$ \\
\hline \multicolumn{5}{|l|}{ GSH-px (U/g Hb) } \\
\hline control & $188.7 \pm 23.7$ & $195.3 \pm 11.3$ & $194.0 \pm 13.0$ & $201.9 \pm 13.3$ \\
\hline Cremophor & $185.9 \pm 16.0$ & $218.4 \pm 18.5$ & $219.3 \pm 16.4$ & $225.5 \pm 18.4$ \\
\hline $\mathrm{SIH}$ & $154.6 \pm 13.7$ & $170.3 \pm 7.1$ & $182.0 \pm 10.6$ & $220.0 \pm 12.8 \mathbf{i}$ \\
\hline
\end{tabular}

LD - lactate dehydrogenase, GSH-px - glutathion peroxidase

Statistical significance: i - compared to the initial value, \# - compared to the control group, c - compared to the Cremophor group 
hydrogenase (LD), and glutathione peroxidase (GSH-px) at the end of the experiment in comparison with the initial values (Table 1). However, the initial value of calcium concentration was significantly higher in comparison with the values in the control and Cremophor group. The activity of LD was significantly higher at the end of the experiment even in comparison with the control and Cremophor groups. The administration of Cremophor induced the same changes in LD, phosphate, and Fe; in addition, a decrease in potassium and albumin concentrations could be observed at the end of the experiment. In the control group, an increase in sodium and GSH and a decrease in urea and phosphates were apparent. These changes were statistically significant only in comparison with the corresponding initial values. The other observed changes were only transient without any permanent trends.

Haematological parameters: Table 2 shows that there were no significant differences in the determined haematological parameters between the SIH, Cremophor, and control groups. Administration of SIH caused an increase in the thrombocytes count during the experiment.

Echocardiographic measurements: The results of LV EF obtained by $\mathrm{M}$ mode echocardiography from the parasternal long axis view and by 2D echocardiography from the parasternal short axis view were very close to each other. No significant changes in LV EF were observed during the experiment in any of the groups. The values of the LV EF oscillated between 59.2-62.5\% in the control group, $60.2-64.4 \%$ in the Cremophor group and 59.1-62.6\% in the SIH group (Fig. 2).

Systolic time interval (PEP/LVET index): No significant changes in PEP/LVET indices were observed during the whole time-course of the study in any of the groups (Fig. 3 ). The relative values (in comparison with the initial values) were oscillating between 99.2 and $114.0 \%$ in the control group, $100.6-105.8 \%$ in the Cremophor group, and 97.7-101.2 \% in the SIH group, resp.

Invasive haemodynamic measurements: The values of mean arterial blood pressure and the values of heart rate did not significantly differ between the groups. An increase in left ventricular $\mathrm{dP} / \mathrm{dt}_{\max }$ was observed in the $\mathrm{SIH}$ group, the values were significantly higher comparing with the other groups (Table 3).

Histological evaluation: Only mild focal damage of the myocardium was present in SIH-treated animals, characterized by groups of cardiomyocytes with eosinophilic (intensely stained) cytoplasm. Locally, scatter necrotic or destroyed cells were found, accompanied by a mild infiltrate of residual inflammatory cells (lymphocytes and above all macrophages) indicating initiation of a reparative process. There were no substantial differences in the damage of the myocardium when comparing the SIH and Cremophor groups.

SIH administration caused focal changes, mostly of medium intensity, in the renal parenchyma - in the cortex and partly also in the medulla. The hyaline degeneration and

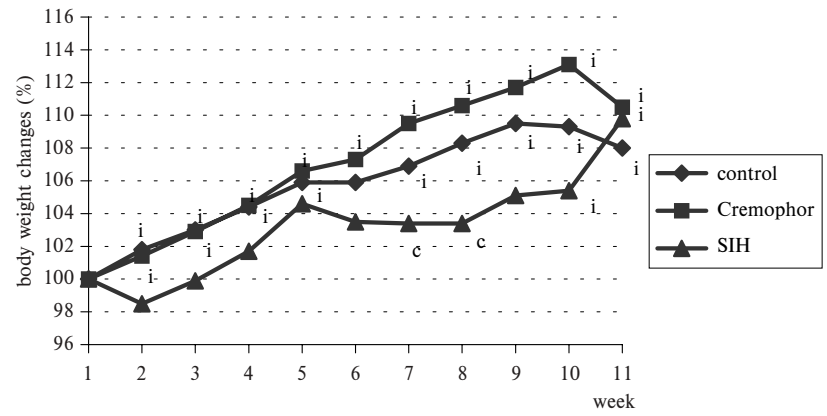

Fig. 1: Body weight changes (\%) in the control, Cremophor and SIH treated rabbits during the experiment (11 weeks). The initial values of body weight were $3.64 \pm 0.08 \mathrm{~kg}$ in the control group, $3.42 \pm 0.09$ in the Cremophor group and $3.79 \pm 0.08$ in the SIH group. Statistical significance: $\mathrm{i}$ compared to the initial value, c - compared to the Cremophor group.

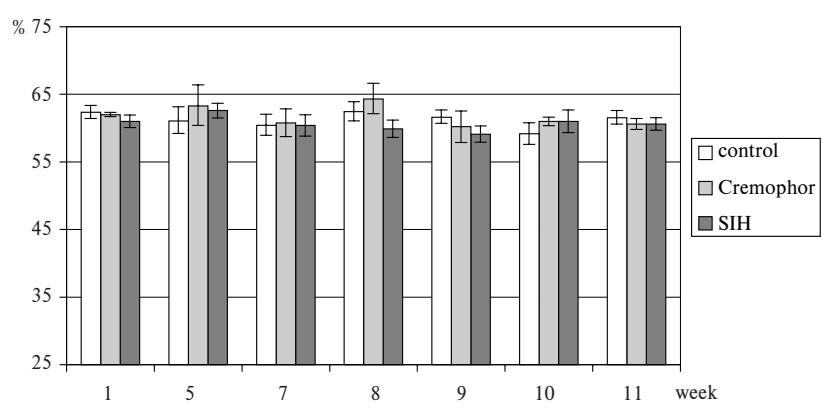

Fig. 2: Changes (\%) of the LV EF obtained by conventional steered M mode echocardiography.

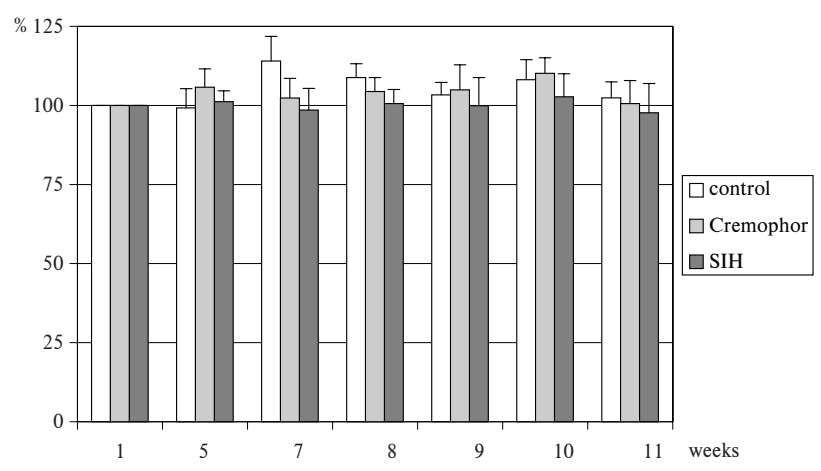

Fig. 3: Changes (\%) of the PEP/LVET index during the experiment.

The absolute initial values (i.e. $100 \%$ ) of the PEP/LVET ratio were $0.432 \pm 0.022$ in the control group, $0.436 \pm 0.014$ in the Cremophor group, and $0.418 \pm 0.013$ in the SIH group, resp. 
Tab. 2: Haematological parameters.

\begin{tabular}{|c|c|c|c|}
\hline Parameter/group & $\begin{array}{l}\text { before the } 1^{\text {st }} \\
\text { administration }\end{array}$ & $\begin{array}{l}\text { before the } 5^{\text {th }} \\
\text { administration }\end{array}$ & $\begin{array}{l}5-7 \text { days after the } \\
10^{\text {th }} \text { administration }\end{array}$ \\
\hline \multicolumn{4}{|c|}{ Leucocytes (x 109/1) } \\
\hline control & $7.1 \pm 0.5$ & $7.0 \pm 0.9$ & $5.7 \pm 0.8$ \\
\hline Cremophor & $6.5 \pm 0.3$ & $6.0 \pm 0.3$ & $5.5 \pm 0.7$ \\
\hline $\mathrm{SIH}$ & $6.8 \pm 0.5$ & $7.0 \pm 0.7$ & $5.6 \pm 0.4$ \\
\hline \multicolumn{4}{|c|}{ Erythrocytes (x 10 12/1) } \\
\hline control & $5.81 \pm 0.18$ & $5.95 \pm 0.11$ & $5.77 \pm 0.15$ \\
\hline Cremophor & $5.84 \pm 0.18$ & $5.56 \pm 0.14$ & $5.68 \pm 0.12$ \\
\hline SIH & $5.81 \pm 0.08$ & $5.66 \pm 0.11$ & $5.63 \pm 0.13$ \\
\hline \multicolumn{4}{|c|}{ Haemoglobin $(\mathrm{g} / \mathrm{l})$} \\
\hline control & $128.2 \pm 3.5$ & $132.1 \pm 2.1$ & $130.0 \pm 2.5$ \\
\hline Cremophor & $128.1 \pm 3.1$ & $126.7 \pm 2.9$ & $129.5 \pm 2.2$ \\
\hline $\mathrm{SIH}$ & $129.2 \pm 1.5$ & $128.2 \pm 1.5$ & $127.2 \pm 1.8$ \\
\hline \multicolumn{4}{|l|}{ Hematocrit } \\
\hline control & $0.387 \pm 0.014$ & $0.413 \pm 0.008$ & $0.398 \pm 0.009$ \\
\hline Cremophor & $0.399 \pm 0.009$ & $0.393 \pm 0.008$ & $0.391 \pm 0.008$ \\
\hline SIH & $0.388 \pm 0.003$ & $0.385 \pm 0.004$ & $0.389 \pm 0.006$ \\
\hline \multicolumn{4}{|l|}{ MCV (fl) } \\
\hline control & $66.4 \pm 0.8$ & $69.4 \pm 1.0 \mathbf{i}$ & $69.1 \pm 0.7$ \\
\hline Cremophor & $68.8 \pm 1.1$ & $70.8 \pm 0.8$ & $68.9 \pm 1.0$ \\
\hline SIH & $66.8 \pm 0.9$ & $68.1 \pm 0.8$ & $69.0 \pm 0.8$ \\
\hline \multicolumn{4}{|l|}{ RDW (\%) } \\
\hline control & $15.1 \pm 0.6$ & $13.8 \pm 0.4$ & $13.8 \pm 0.3$ \\
\hline Cremophor & $13.8 \pm 0.6$ & $13.4 \pm 0.3$ & $14.4 \pm 0.5$ \\
\hline SIH & $13.4 \pm 0.2$ & $13.5 \pm 0.2$ & $14.1 \pm 0.3$ \\
\hline \multicolumn{4}{|c|}{ Thrombocytes (x 109/1) } \\
\hline control & $417 \pm 31$ & $417 \pm 27$ & $429 \pm 31$ \\
\hline Cremophor & $330 \pm 21$ & $352 \pm 19$ & $370 \pm 31$ \\
\hline $\mathrm{SIH}$ & $341 \pm 18$ & $443 \pm 28 \mathbf{i}$ & $454 \pm 26 \mathbf{i}$ \\
\hline
\end{tabular}

MCV - mean cell volume, RDW - red cell distribution width

Statistical significance: $\mathrm{i}$ - compared to the initial value

Tab. 3: The invasive haemodynamic measurements.

\begin{tabular}{|l|c|c|c|}
\hline & $\begin{array}{c}\mathbf{d P} / \mathbf{d t}_{\text {max }} \\
\left(\mathrm{mmHg}^{-1}\right)\end{array}$ & $\begin{array}{c}\text { BP } \\
(\mathrm{mmHg})\end{array}$ & $\begin{array}{c}\text { HR } \\
\left(\mathrm{min}^{-1}\right)\end{array}$ \\
\hline Control (n=11) & $9338 \pm 647$ & $101.3 \pm 3.2$ & $297 \pm 8$ \\
\hline Cremophor (n=12) & $8644 \pm 665$ & $99.2 \pm 4.1$ & $309 \pm 6$ \\
\hline SIH (n=8) & $13354 \pm 1191 \#, \mathbf{c}$ & $101.0 \pm 3.9$ & $321 \pm 14$ \\
\hline
\end{tabular}

$\mathrm{dP} / \mathrm{dt}_{\max }$-maximal pressure rise in the isovolumic phase of left ventricular contraction; BP-mean arterial blood pressure; HR-heart rate

Statistical significance: \# - compared to the control group, c - compared to the Cremophor group 

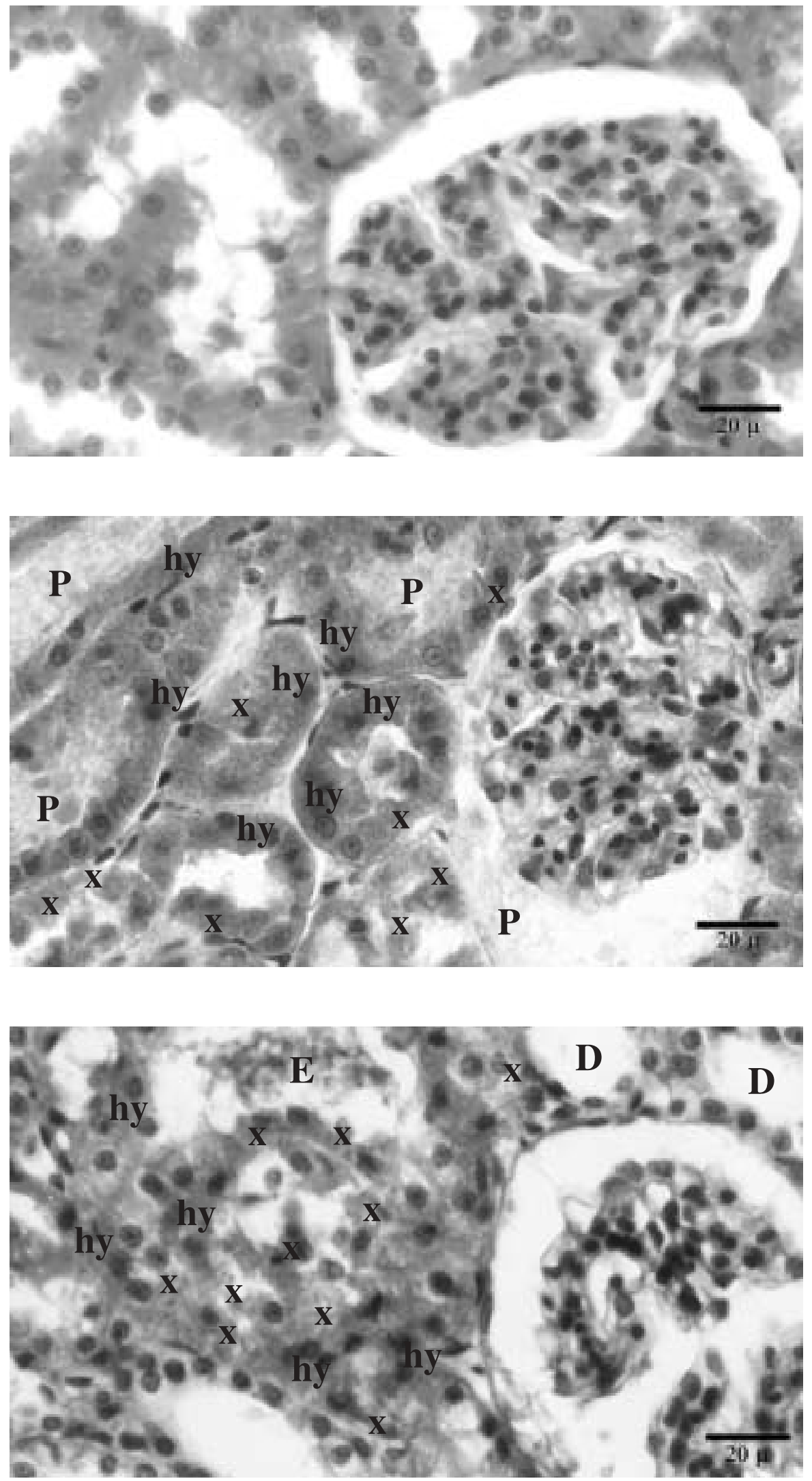

Fig. 4: CONTROL group - the renal cortex with the renal corpuscle and proximal convoluted tubules. Haematoxylin and eosin.

Fig. 5: CREMOPHOR group protein precipitate $(\mathrm{P})$ in the slit between the visceral layer (podocytes) and parietal layer of Bowmann's capsule as well as within the lumen of some tubules; hyaline degeneration (hy) of the epithelium of proximal tubules (cells with intensely eosinophilic cytoplasm) and scatter necrotic cells (x) are characteristic. Haematoxylin and eosin.

Fig. 6: SIH group - conspicuous hyaline degeneration (hy) and necrosis of cells (x) above all of the proximal, less of the distal tubules; cell remnants inside the lumen of tubules form here and there the epithelial casts (E); D distal convoluted tubules. Haematoxylin and eosin. 
less necrosis of epithelial cells above all of proximal convoluted tubules were characteristic changes in the majority of treated rabbits (Fig. 6). Lumina of those tubules frequently contained the casts of granular proteinaceous material in a typical crescent formation enlarged the slit of Bowman's capsule to compress the tuft of glomerular capillaries. Similar changes, however of a less extent, were also present in some few rabbits treated with $10 \%$ Cremophor (Fig. 5) in contrast to intact animals in the control group (Fig. 4).

The other examined tissues (the liver, lung, small intestine, and muscle tissue) were devoid of any significant pathological changes.

Body weight: A significant body weight increase was present in all groups (Fig. 1); the body weight gain at the end of the experiment was $108.0 \%$ in the control, $110.5 \%$ in the Cremophor, and $109.8 \%$ in the SIH group, resp. No premature deaths of animals occurred following the administration of PIH or in other groups.

\section{Discussion}

The SIH - an analogue of the PIH - is a highly effective iron chelator with antioxidant and antimalarial activities, documented in a number of in vitro studies $(1,8,9,13,16$, $17,18,24,25)$. The antimalarial properties of SIH were also documented in vivo (6). According to these data, SIH seems to be a very promising substance for the therapy of various pathological conditions, like free radical-mediated injury or malaria. However, no toxicological data obtained from in vivo studies have been available yet. This is the first study focused on the evaluation of potential toxic effects of SIH on selected parameters.

Due to very low water solubility, the $\mathrm{SIH}$ - as well as the PIH $(10,19,20,21)$ - had to be partially dissolved in a $10 \%$ Cremophor solution and administered intraperitoneally. The dose of SIH administered to rabbits $(50 \mathrm{mg} / \mathrm{kg})$ is nearly equivalent to the dose of $\mathrm{PIH}$ used in our previous studies $(10,19,20)$ due to a very close molecular weight of both chelators (286 Da PIH vs. 240 Da SIH).

Echocardiography is a well-established non-invasive method for the determination of left ventricular systolic function both in clinical and experimental settings (14). No significant changes in LV EF have been found in any of studied groups. Determination of the systolic time intervals is also a well-based method for the left ventricular systolic function examination, as the PEP/LVET ratio is known to increase when the left ventricular performance is compromised (5). No significant changes in this index have been noticed. A significantly higher left ventricular contractility (as determined by $\mathrm{dP} / \mathrm{dt}_{\max }$ ) could be observed in the $\mathrm{SIH}$ receiving group. However, this increase was not accompanied by blood pressure alterations and non-invasive parameters mentioned above indicated no changes in the left ventricular systolic function. Moreover, in an in vitro study by Horackova et al. (9), who studied the antioxidant effects of SIH in adult cardiomyocytes (9), SIH itself did not affect contractile activity in isolated cardiomyocytes. The fact that increased contractility of myocardium caused by repeated SIH administration in this study was not accompanied by an increase in blood pressure may be due, at least partly, to the released salicylaldehyde from SIH by cleavage of hydrazone bond and its counteracting vasodilating action (7).

Only slight changes in biochemical and haematological parameters were observed in SIH-treated rabbits; the values generally did not differ from the values found in the control or Cremophor groups. Therefore, they should not necessarily be attributed to SIH administration. A decrease in calcium concentrations in SIH-treated rabbits has to be interpreted with caution, since the initial value was higher than in the control and Cremophor groups, possibly due to the variation of the biochemical parameters in individual rabbits (11). Lactate dehydrogenase is a rather non-specific parameter - an increase in its activity can be incited due to, e.g. the haemolysis, heart attack, liver or muscle disease (15). None of the above-mentioned conditions could be confirmed by other findings in our experiment. An increased activity of GSH-px could prove the antioxidant properties of this Fe chelator, demonstrated in in vitro studies, too $(8,9,18)$. The physiological range for the thrombocyte count is quite large (11), so that the increase in values observed in the SIH group seems to lack any clinical importance.

SIH induced morphological changes in the epithelium of convoluted tubules and accumulation of the proteinaceous material inside some renal corpuscles (especially near the medulla). The same type of the damage, but of less extent, was also observed in some rabbits treated only with the vehiculum of SIH - $10 \%$ Cremophor solution. On the other hand, the determined values in biochemical parameters did not reveal any deterioration of kidney functions in SIH or Cremophor treated rabbits. In the examined material, only a relatively small number of affected tubules as well as glomeruli were observed. Therefore, the compensation of the function was still possible, so that the morphological changes have not been followed by significant changes in biochemical parameters.

Cremophor (a polyoxyethylated castor oil) has been used as a solvent for several water-insoluble drugs, including cyclosporine, teniposide, and diazepam. Due to the observations of other authors, this vehicle might not be physiologically inert (3). Even though the incidence of nephrotoxicity caused by the administration of Cremophor was observed in rats $(2,22)$, any morphologic or functional changes after Cremophor administration could be observed in the rabbits (23).

Mild morphological changes within the myocardium should not be interpreted as a consequence of the SIH treatment, because of similar changes observed in the Cremophor group.

Furthermore, an increase in the body weight - comparable in the control and Cremophor groups - indicates that repeated administration of SIH was well tolerated by rabbits. 


\section{Conclusions}

The results of our study demonstrated that intraperitoneal administration of SIH to rabbits in a dose of $50 \mathrm{mg} / \mathrm{kg}$, injected once weekly for 10 weeks, did not exhibit marked signs of toxicity, which is a very important finding in relation to intended future clinical application. The administration of SIH was well tolerated (zero mortality and weight gain). The exceptional changes in haematological and biochemical parameters, as well as in parameters of cardiac function seem not to be of major importance. The mild morphological changes in kidney parenchyma do not seem to affect the function of this organ as documented by the biochemical evaluation. The obtained data can be considered promising from the standpoint of possible clinical use of SIH in some pathological states.

\section{Acknowledgments}

The authors wish to thank Mrs. Ludmila Koželuhová for her technical assistance. This study was supported by a Grant GA CR 305/03/1511 and Research Project CEZ 111600002.

\section{References}

1. Barker $\mathrm{E}$, Vitolo $\mathrm{M}$, Webb $\mathrm{J}$. Iron chelation by pyridoxal isonicotinoyl hydrazon and analogues in hepatocytes in culture. Biochem Pharmacol 1983;34:298-302.

2. Besarab A, Jarrell BE, Hirsch S, Carabasi RA, Cressman MD, Green P. Use of the isolated perfused kidney model to assess the acute pharmacologic effects of cyclosporine and its vehicle, cremophor EL. Transplantation 1987;44:195-201.

3. Dorr TR. Pharmacology and toxicology of Cremophor EL diluent. Ann Pharmacother 1994;28(suppl 5):S11-S14.

4. Faa G, Crisponi G. Iron chelating agents in clinical practice. Coord Chem Rev 1999; 184:291-310.

5. Ganong WF. Review of medical physiology. $19^{\text {th }}$ edition. New York: Lange Medical Books, 1997:542.

6. Golenser J, Domb A, Teomim D. The treatment of animal models of malaria with iron chelators by use of a novel polymeric device for slow drug release. J Pharmacol Exper Therap 1997;281:1127-35.

7. Hardman JG, Limbird LE, eds. Goodman\&Gilman's The pharmacological basis of therapeutics. $10^{\text {th }}$ ed. New York: McGraw-Hill, 2001:698.

8. Hermes-Lima M, Santos NCF, Yan J, Andrews M, Schulman HM, Ponka P. EPR spin trapping and 2-deoxyribose degradation studies of the effect of pyridoxal isonicotinoyl hydrazone (PIH) on. $\mathrm{OH}$ formation by the Fenton reaction. Bioch Bioph Acta 1999;1426:475-82.

9. Horackova M, Ponka P, Byczko Z. The antioxidant effects of a novel iron chelator salicylaldehyde isonicotinoyl hydrazone in the prevention of $\mathrm{H}_{2} \mathrm{O}_{2}$ injury in adult cardiomyocytes. Cardiovasc Res 2000;47:529-36.
10. Klimtová I, Šimůnek T, Geršl V et al. Biochemical and haematological changes following reapeated pyridoxal isonicotinoyl hydrazone administration in rabbits. Biomarkers Environ 2001;4(suppl 1):70-2.

11. Kraus AL, Weisbroth SH, Flatt RE, Brewer N. Biology and diseases of rabbits. In Fox JG, Cohen BJ, Loew FM, eds. Laboratory animal medicine. Orlando: Academic Press, 1984:212-3.

12. Lieu PT, Heiskala M, Peterson PA, Yang Y. The roles of iron in health and disease. Mol Asp Med 2001;22:1-87

13. Ponka P, Borová J, Neuwirt J, Fuchs O, Nečas E. A study of intracellular iron metabolism using pyridoxal isonicotinoyl hydrazone and other synthetic chelating agents. Bioch Biophys Acta 1979;586:278-97.

14. Pye MP, Black M, Cobbe SM. Comparison of in vivo and in vitro haemodynamic function in experimental heart failure: use of echocardiography. Cardiovasc Res 1996;31:873-81.

15. Racek J et al. Klinická biochemie. 1. ed. Praha: Galen, 1999:80

16. Richardson DR, Ponka P. Development of iron chelators to treat iron overload disease and their use as experimental tools to probe intracellular iron metabolism. Am J Hematol 1998;58:299-305.

17. Richardson DR, Ponka P. Pyridoxal isonicotinoyl hydrazone and its analogs: Potential orally effective iron-chelating agents for the treatment of iron overload disease. J Lab Clin Med 1998:131:306-14.

18. Schulman HM, Hermes-Lima M, Wang E-M, Ponka P. In vitro antioxidant properties of the iron chelator pyridoxal isonicotinoyl hydrazone and some of its analogs. Redox Report 1996;1:373-8.

19. Šimůnek T, Klimtová I, Geršl V et al. Effects of 10-week pyridoxal isonicotinoyl hydrazone administration on selected organ systems in rabbits (abstract). Acta Med (Hradec Králové) 2001;44:64.

20. Šimůnek T, Klimtová I, Hrdina R et al. The effects of repeated administration of pyridoxal isonicotinoyl hydrazone on cardiovascular system in rabbits. Biomarkers Environ 2001:4(suppl 1):70-2.

21. Sookvanichsilp N, Nakornchai S, Weerapradist W. Toxicological study of pyridoxal isonicotinoyl hydrazone: acute and subchronic toxicity. Drug Chem Toxicol 1991; 14:395-403.

22. Thiel G, Hermle M, Brunner FP. Acutely impaired renal function during intravenous administration of cyclosporine A: a cremophore side-effects. Clin Nephrol 1986;25(suppl 1):S40-2

23. Thliveris JA, Yatscoff RW, Lukowski MP, Copeland KR, Jeffery JR, Murphy GF Chronic cislosporin nephrotoxicity: A rabbit model. Neph 1991;57:470-6.

24. Tsafack A, Loyevsky M, Ponka P, Cabantchik ZI. Mode of action of iron (III) chelators as antimalarials. IV. Potentiation of desferal action by benzoyl and isonicotinoyl hydrazone derivatives. J Lab Clin Med 1996;127:574-82.

25. Zanninelli G, Glickstein H, Breuer W et al. Chelation and mobilization of cellular iron by different classes of chelators. Mol Pharmacol 1997;51:842-52.

Submitted February 2003.

Accepted August 2003.

Mgr. Ivona Klimtová,

Charles University in Prague, Faculty of Pharmacy in Hradec Králové, Department of Pharmacology and Toxicology, Heyrovského 1203, 50005 Hradec Králové, Czech Republic. e-mail: klimtova@faf.cuni.cz 